\title{
MELOGEN: an EST database for melon functional genomics
}

\author{
Daniel Gonzalez-Ibeas' ${ }^{1}$ José Blanca ${ }^{2}$, Cristina Roig², Mireia González-To ${ }^{3}$, \\ Belén Picó ${ }^{2}$, Verónica Truniger ${ }^{1}$, Pedro Gómez ${ }^{1}$, Wim Deleu ${ }^{3}$, \\ Ana Caño-Delgado ${ }^{4}$, Pere Arús ${ }^{3}$, Fernando Nuez ${ }^{2}$, Jordi Garcia-Mas ${ }^{3}$, \\ Pere Puigdomènech ${ }^{4}$ and Miguel A Aranda*1
}

\begin{abstract}
Address: ${ }^{1}$ Departamento de Biología del Estrés y Patología Vegetal, Centro de Edafología y Biología Aplicada del Segura (CEBAS)- CSIC, Apdo. correos 164, 30100 Espinardo (Murcia), Spain, ${ }^{2}$ Departamento de Biotecnología, Instituto de Conservación y Mejora de la Agrodiversidad Valenciana (COMAV-UPV), Camino de Vera s/n, 46022 Valencia, Spain, ${ }^{3}$ Departament de Genètica Vegetal, Centre de Recerca en Agrigenòmica CSIC-IRTA, Carretera de Cabrils Km2, 08348 Cabrils (Barcelona), Spain and ${ }^{4}$ Departament de Genètica Molecular, Centre de Recerca en Agrigenòmica CSIC-IRTA, Jordi Girona 18-26, 08034 Barcelona, Spain

Email: Daniel Gonzalez-Ibeas - agr030@cebas.csic.es; José Blanca - jblanca@btc.upv.es; Cristina Roig - croig@btc.upv.es; Mireia GonzálezTo - tmp2115@irta.es; Belén Picó - mpicosi@btc.upv.es; Verónica Truniger - truniger@cebas.csic.es; Pedro Gómez - pglopez@cebas.csic.es; Wim Deleu -wim.deleu@irta.es; Ana Caño-Delgado - acdgm1@cid.csic.es; Pere Arús - pere.arus@irta.es; Fernando Nuez - fnuez@btc.upv.es; Jordi Garcia-Mas - Jordi.Garcia@IRTA.ES; Pere Puigdomènech - pprgmp@ibmb.csic.es; Miguel A Aranda* - m.aranda@cebas.csic.es

* Corresponding author
\end{abstract}

Published: 3 September 2007

BMC Genomics 2007, 8:306 doi:10.1/86/|47|-2164-8-306
Received: 8 May 2007

Accepted: 3 September 2007

This article is available from: http://www.biomedcentral.com//47/-2/64/8/306

C 2007 Gonzalez-lbeas et al; licensee BioMed Central Ltd.

This is an Open Access article distributed under the terms of the Creative Commons Attribution License (http://creativecommons.org/licenses/by/2.0), which permits unrestricted use, distribution, and reproduction in any medium, provided the original work is properly cited.

\begin{abstract}
Background: Melon (Cucumis melo L.) is one of the most important fleshy fruits for fresh consumption. Despite this, few genomic resources exist for this species. To facilitate the discovery of genes involved in essential traits, such as fruit development, fruit maturation and disease resistance, and to speed up the process of breeding new and better adapted melon varieties, we have produced a large collection of expressed sequence tags (ESTs) from eight normalized cDNA libraries from different tissues in different physiological conditions.
\end{abstract}

Results: We determined over 30,000 ESTs that were clustered into 16,637 non-redundant sequences or unigenes, comprising 6,023 tentative consensus sequences (contigs) and 10,614 unclustered sequences (singletons). Many potential molecular markers were identified in the melon dataset: I,052 potential simple sequence repeats (SSRs) and 356 single nucleotide polymorphisms (SNPs) were found. Sixty-nine percent of the melon unigenes showed a significant similarity with proteins in databases. Functional classification of the unigenes was carried out following the Gene Ontology scheme. In total, 9,402 unigenes were mapped to one or more ontology. Remarkably, the distributions of melon and Arabidopsis unigenes followed similar tendencies, suggesting that the melon dataset is representative of the whole melon transcriptome. Bioinformatic analyses primarily focused on potential precursors of melon micro RNAs (miRNAs) in the melon dataset, but many other genes potentially controlling disease resistance and fruit quality traits were also identified. Patterns of transcript accumulation were characterised by Real-Time-qPCR for 20 of these genes.

Conclusion: The collection of ESTs characterised here represents a substantial increase on the genetic information available for melon. A database (MELOGEN) which contains all EST sequences, contig images and several tools for analysis and data mining has been created. This set of sequences constitutes also the basis for an oligo-based microarray for melon that is being used in experiments to further analyse the melon transcriptome. 


\section{Background}

Melon (Cucumis melo L.) is an important horticultural crop grown in temperate, subtropical and tropical regions worldwide. Melon is among the most important fleshy fruits for fresh consumption, its total production in 2004 exceeding 874 million metric tons, of which $72.5 \%$ are produced in Asia, 11.7\% in Europe, $8.4 \%$ in America and $6.1 \%$ in Africa, being a significant component of fresh fruit traded internationally [1]. Melon belongs to the Cucurbitaceae family, which comprises up to 750 different species distributed in 90 genera. Species in this family include watermelon, cucumber, squash and marrow, all of them cultivated essentially because of their fruits, but this family also includes species of interest for other reasons, as, for example, their contents in potentially therapeutic compounds (e.g. Momordica charantia) [2]. Melon is a diploid species, with a basic number of chromosomes $\mathrm{x}=12(2 \mathrm{x}=2 \mathrm{n}=24)$ and an estimated genome size of 450 to $500 \mathrm{Mb}$ [3], similar in size to the rice genome (419 Mb) $[4,5]$ and about three times the size of the Arabidopsis genome $(125 \mathrm{Mb})$ [6]. Melon has been classified into two subspecies, C. melo ssp. agrestis and C. melo ssp. melo with India and Africa being their centres of origin, respectively $[7,8]$.

Melon has a great potential for becoming a model for understanding important traits in fruiting crops. Melon fruits have wide morphological, physiological and biochemical diversity $[7,9]$ which can be exploited to dissect biological processes of great technological importance, among them flavour development and textural changes that occur during fruit ripening. The contemporary melon cultivars can be divided into two groups, climacteric and nonclimacteric, according to their ripening patterns [10]. Climacteric fruits are characterized by rapid and profound changes during ripening associated to increased levels of respiration and release of ethylene, whereas the nonclimacteric varieties do not produce ethylene and have long shelf-life. Analyses of climacteric and nonclimacteric melons have illustrated the process of aroma formation [1114] and the temporal sequence of cell wall disassembly [15-17]. Melon can be also a very useful experimental system to analyse other aspects of fundamental plant biology. For example, melon and other cucurbits have been used to analyse the development of the plant vasculature and the transportation of macromolecules through it [1820], and different interactions between melon and pests and pathogens have been characterised with varying depths [21-27].

Important genetic tools have been described for melon, as for example linkage genetic maps $[28,29]$ and the development of a genomic library of near isogenic lines (NILs) from an exotic accession [30]; also, biotechnology is feasible in melon [31-33]. However, the great majority of genes involved in the aforementioned traits are yet to be identified in melon. Partial sequencing of cDNA inserts of expressed sequence tags (ESTs) have been used as an effective method for gene discovery. By sequencing clones derived from RNA from different sources, and/or by normalizing cDNA libraries, the total set of genes sampled can be maximized. Bioinformatic analysis, annotation and clustering of sequences could yield databases which mining can be used to select candidate genes implicated in traits of interest. EST collections can also serve to construct microarrays useful for identifying sets of plant genes expressed during different developmental stages and/or responding to environmental stimuli $[34,35]$. In addition, EST collections are good sources of simple sequence repeats (SSRs) and single-nucleotide polymorphisms (SNPs) that can be used for creating saturated genetic maps [36,37]. Thus, EST collections have been generated for many plant species, being the most comprehensive those of Arabidopsis[6] and rice [38]. Fruit crops have been less extensively surveyed, but important collections are publicly available for several species, including tomato [39], apple [40], grape [41] and citrus [42].

Despite the importance of the family Cucurbitaceae, relatively little EST information is currently available: only 16,039 nucleotide sequences have been annotated from the whole Cucurbitaceae family in the publicly accessible GenBank database as of November 2006; out of these, 12,180 correspond to the Cucumis genus and 6,061 to melon. These numbers are in sharp contrast with the data available for families composed of other important food crops like Solanaceae (1,020,102 sequences), Fabaceae $(1,466,518$ sequences $)$, Brassicaceae $(1,010,148$ sequences excluding Arabidopsis), Vitaceae $(449,478)$ and Rosaceae (390,066 sequences). Here we describe a public EST sequencing project in melon. We report the determination and analysis of 30,675 high-quality melon ESTs, sequenced from eight normalized cDNA libraries corresponding to different tissues in different physiological conditions. We have classified the sequences into functional categories and described SSRs and SNPs of potential use in genetic maps and marker-assisted breeding programs. A database which contains all EST sequences, contig images and several tools for analysis and data mining has been created. In addition, we have analyzed the EST melon dataset to identify candidate genes potentially coding microRNAs or involved in fruit maturation processes and pathogen defence. The pattern of transcript accumulation in different physiological conditions has been characterised by Real-Time-qPCR for 20 of these candidate genes. 


\section{Results \\ EST Sequencing and Clustering}

Eight cDNA libraries were constructed using material from "Piel de Sapo" Spanish cultivars, the C-35 cantaloupe line (both belonging to Cucumis melo L. ssp. melo) and the accession pat81 of C. melo L. ssp. agrestis (Naud.) Pangalo. The sources of RNA to construct each library were fruits of 15 and 46 days after pollination (dap), leaves, photosynthetic cotyledons inoculated with Cucumber mosaic virus (CMV), healthy roots and Monosporascus cannonballus Pollack et Uecker (the causal agent of melon vine decline) infected roots (Table 1). Approximately 3,700 sequences were determined from each library by single-pass 5' sequencing, except for the library prepared from CMV infected cotyledons for which approximately 6,600 sequences were determined, yielding a total of 33,292 raw sequences. Processing to eliminate vector sequences, low quality chromatograms and sequences of less than 100 base pairs (bp) gave rise to 29,604 good quality expressed sequence tags (ESTs) (Table 2) implying a cloning success of approximately $89 \%$. The average edited length was $674 \mathrm{bp}$, and only a $6.4 \%$ of the sequences had less than $350 \mathrm{bp}$.

Clustering of the sequences using default parameters of the EST analysis pipeline EST2uni [43] yielded 6,023 tentative consensus sequences (also called contigs) and 10,614 unclustered sequences (also called singletons), with a total of 16,637 non-redundant sequences or unigenes (Table 2). All good quality ESTs were used for clustering, independently of the melon genotype of origin, because single nucleotide polymorphisms (SNPs) were expected among genotypes. The number of ESTs per unigene was between 1 and 44 ( 1 case), with an average of 1.8 ESTs per contig, as a high proportion of contigs (4,886 out of 6,023$)$ contained less than 5 ESTs and contigs with more than 8 ESTs were scarce (Fig. 1A). Therefore, redundancy values were notably low (around 16\%). The unigene length varied between $101 \mathrm{bp}$ and 2,664 bp, averaging $751 \mathrm{bp}$ (Fig. 1B). Library specific unigenes were about one third of the total for each library (Table 2). A second round of clustering yielded 14,480 unigene clusters, referred to as superunigenes. A web integrated data- base that contains all EST sequences, contig images and several tools for analysis and data mining has been created and named MELOGEN [44]. Codon usage was estimated using this EST collection. As expected, the codon usage of melon was very similar to that of Arabidopsis and other dicots. The preferred stop codon was UGA occurring in the $48 \%$ of the sequences. Suppression of the CG dinucleotide in the last two codon positions is very frequent in dicots, possibly as a consequence of methylation of $\mathrm{C}$ in the CG dinucleotide, resulting in an increased mutation rate [45]; in agreement with these data, the ratio XCG/ XCC for melon was 0.52 , very similar to the corresponding figure for tomato $(0.58)$, pea $(0.51)$, potato $(0.48)$ and other dicots [45].

Libraries obtained from tissues inoculated with M. cannonballus were expected to contain sequences from the fungus. To estimate the proportion of sequences of fungal origin in these libraries, BLAST analyses against a database with plant and fungal sequences were carried out [46]. Only 56 sequences from these libraries were found to have a more significant similarity with fungal sequences than with plant sequences (Table 3). Consequently, these sequences were considered of fungal origin [46].

\section{SSRs and SNPs}

We have analysed the nature and frequency of microsatellites or simple sequence repeats (SSRs) in the melon sequence dataset. A search for repeats of two, three or four nucleotides in the dataset yielded 1,052 potential SSRs. Approximately, $6 \%$ of the unigenes contained at least one of the considered SSRs motifs, with repeats of three nucleotides being prevalent (Table 4). The maximum and minimum lengths of the repeats were 68 and 17 nucleotides, respectively, and the average length was 26 nucleotides. The most common repeat among dinucleotides was, by far, the AG repeat, constituting the $83 \%$ (Table 4 ). Repeats of AT and AC dinucleotides followed, with approximately $9 \%$ and $7 \%$, respectively. Among the trinucleotide repeats, the most frequent was AAG (66\%, Table $4)$, and the least frequent was ACT (0.6\%, Table 4$)$. Among tetranucleotide repeats, the most frequent was AAAG (51\%, Table 4). A high proportion of SSRs (29.5\%)

Table I: Description of cDNA libraries

\begin{tabular}{lll}
\hline Name & Subspecies/cultivar/accession & Tissue/physiological condition \\
\hline I5d & Ssp. melo cv. "Piel de Sapo" T-III & Fruit I5 days after pollination \\
46d & Ssp. melo cv. "Piel de Sapo" T-III & Fruit 46 days after pollination \\
A & Ssp. agrestis accession pat8I & Roots \\
Al & Ssp. agrestis accession pat8I & Roots infected with M. cannonballus \\
CI & Ssp. melo var. cantaloupe accession C-35 & Photosynthetic cotyledons infected with CMV \\
HS & Ssp. melo var. cantaloupe accession C-35 & Leaves \\
PS & Ssp. melo cv. "Piel de Sapo" Piñonet torpedo & Roots \\
PSI & Ssp. melo cv. "Piel de Sapo" Piñonet torpedo & Roots infected with M. cannonballus
\end{tabular}


Table 2: EST statistics

\begin{tabular}{|c|c|c|c|c|c|c|c|c|c|}
\hline Library & $\begin{array}{l}\text { Raw } \\
\text { sequences }\end{array}$ & $\begin{array}{l}\text { Good-Quality } \\
\text { ESTs }\end{array}$ & EST length & Singletons & Contigs & Unigenes & Redundancy (\%) & $\begin{array}{l}\text { Library-specific } \\
\text { unigenes }\end{array}$ & Novelty (\%) \\
\hline $15 d$ & 3,936 & 3,582 & $608.1 \pm 175.2$ & 1,009 & 1,930 & 2,939 & 18 & 1,100 & 37 \\
\hline $46 d$ & 3,840 & 3,493 & $583.0 \pm 161.1$ & 1,000 & $\mathrm{I}, 854$ & 2,854 & 18 & 1,063 & 37 \\
\hline$A$ & 3,936 & 3,666 & $700.0 \pm 185.4$ & 1,289 & 1,900 & 3,189 & 13 & 1,365 & 43 \\
\hline $\mathrm{Al}$ & 3,647 & 3,255 & $756.3 \pm 137.1$ & 928 & 1,688 & 2,616 & 20 & $\mathrm{I}, 005$ & 38 \\
\hline $\mathrm{Cl}$ & 6,605 & 5,664 & $651.4 \pm 205.7$ & 2,089 & 2,590 & 4,679 & 17 & 2,264 & 48 \\
\hline HS & 3,648 & 3,012 & $669.3 \pm 171.1$ & 939 & 1,609 & 2,548 & 15 & 998 & 39 \\
\hline PS & 3,840 & 3,377 & $679.9 \pm 198.7$ & 1,179 & 1,766 & 2,945 & 13 & 1,258 & 43 \\
\hline \multirow[t]{2}{*}{ PSI } & 3,840 & 3,555 & $749.3 \pm 156.2$ & 1,279 & 1,826 & 3,105 & 13 & 1,363 & 44 \\
\hline & 33,292 & 29,604 & & $10,6 \mid 4$ & 6,023 & 16,637 & & & \\
\hline
\end{tabular}

were found in open reading frames (ORFs), though an analysis of the localization of di-, tri- and tetranucleotides separately showed that di- and tetranucleotides localised preferentially in untranslated regions (UTRs), whereas trinucleotides localised in both, UTRs and ORFs (Table 5).

Single nucleotide polymorphisms (SNPs) are the most abundant variations in genomes and, therefore, constitute a powerful tool for mapping and marker-assisted breeding. We initially identified in the melon sequence dataset 14,074 single nucleotide sequence variations and therefore potential SNPs (pSCH; Table 6) distributed in 4,663 contigs; however, these variations would include highquality SNPs (pSNP) but also sequencing errors and mutations introduced during the cDNA synthesis step. Using more stringent criteria, these figures were substantially reduced: Putative SNPs were annotated only when the least represented allele was present in at least two EST sequences from the same genotype in a given contig and showing the same base change. Two accessions of the same cultivar (cv. "Piel de sapo") represented $47.3 \%$ of the sequences, but more than one half of the sequences were from two other more distant genotypes, the C-35 cantaloupe accession (29.3\%) and the pat81 agrestis accession (23.4\%). Thus, a total of 356 high-quality SNPs were found in 292 contigs, averaging 1.2 SNPs per contig.

Table 3: ESTs showing significant similarity with fungal sequences

\begin{tabular}{ll}
\hline Library & Number of ESTs \\
\hline I5d & 0 \\
$46 d$ & 0 \\
A & 2 \\
AI & 26 \\
Cl & 0 \\
HS & 1 \\
PS & 1 \\
PSI & 30 \\
Total & 60 \\
\hline
\end{tabular}

Transitions were much more common than transversions. There were $117 \mathrm{AG}$ and $112 \mathrm{CT}$ transitions compared with $28 \mathrm{AC}, 37 \mathrm{AT}$ and $33 \mathrm{GT}$ transversions (Table 6). CG transversions were not detected. The MELOGEN database [44] includes a tool for designing oligonucleotide primers to amplify the region containing the polymorphism to generate the corresponding molecular marker.

\section{Functional annotation}

In order to identify melon unigenes potentially encoding proteins with known function, we carried out a BLASTX analysis [47] of the sequence dataset against the databases listed in Table 7. Out of the 13,019 unigenes with a hit with proteins in databases, $11,431(68.7 \%)$ unigenes showing an $E$ value of $\leq 1 \mathrm{e}-10$ were annotated. On the other hand, $31.3 \%$ of the unigenes did not show significant similarity to any protein in the databases and, therefore, were not annotated.

Additionally, we performed a functional classification of the unigenes following the Gene Ontology scheme. Gene Ontology provides a structured and controlled vocabulary to describe gene products according to three ontologies: molecular function, biological process and cellular component [48]. To do that, we added GO terms based on the automated annotation of each unigene using the Arabidopsis database [6]. A summary of the results with the percentage of unigenes annotated in representative categories corresponding to the GO slim terms [48] is shown, as well as a comparison of the distribution of melon and Arabidopsis unigenes (Fig. 2). The distributions of melon and Arabidopsis unigenes follow similar tendencies, suggesting that the melon dataset is representative of the whole melon transcriptome. In total, 9,402 unigenes could be mapped to one or more ontologies, with multiple assignments possible for a given protein within a single ontology. A high percentage of unigenes in both species was classified as "unknown function". Out of the 9,791 assignments made to the cellular component category, $25.8 \%$ corresponded to membrane proteins and $17.8 \%$ to plastidial proteins (Fig. 2A). Under the molecu- 

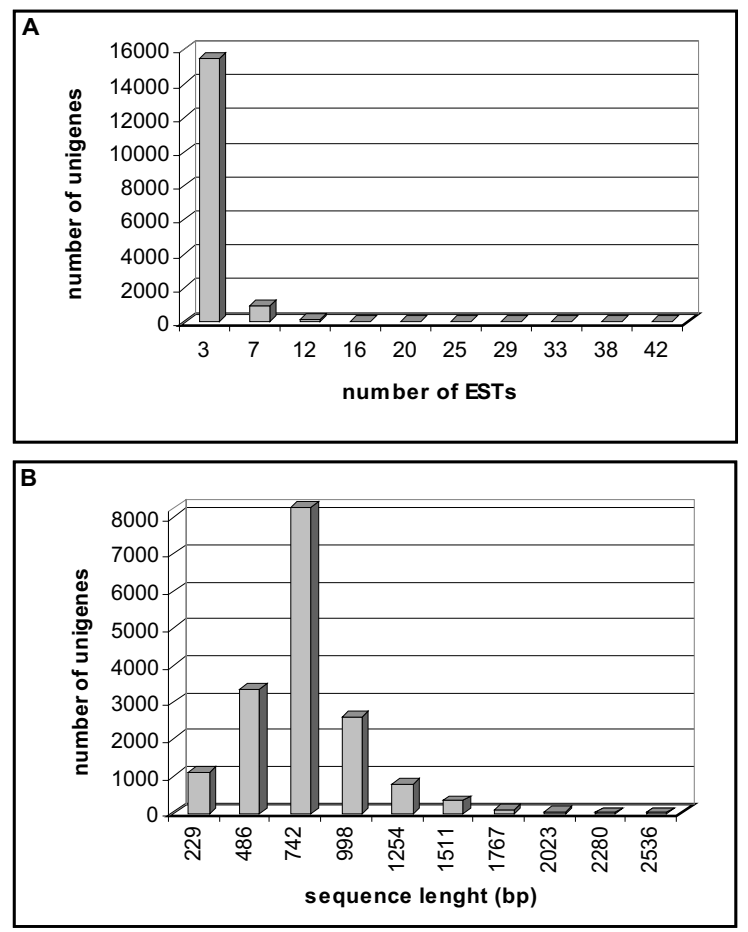

\section{Figure I}

Unigenes statistics. (A) Distribution of melon ESTs among unigenes (contigs and singletons). (B) Size distribution of melon unigenes.

lar function category, assignments were mainly to catalytic activity (23.0\%) and to hydrolase activity (14.7\%) (Fig. $2 \mathrm{~B})$. The distribution of unigenes under the biological process category was more uniform, with $19.9 \%$ of assignments to cellular process and $12.7 \%$ to biosynthesis (Fig. 2C).

We have also identified 6,673 (40.1\%) melon unigenes with an ortholog in the Arabidopsis database, and a HMMER motif has been assigned to 4,655 (28.0\%) unigenes by comparisons with the Pfam database [49] (Table $7)$. All these results are compiled in the MELOGEN database, which also contains direct links to the databases used to carry out analyses.

\section{Genes potentially encoding microRNAs}

Central to RNA silencing are small RNA molecules (sRNAs) that can arise from endogenous or exogenous sources from precursors with double-stranded RNA (dsRNA) pairing. One class of such sRNAs are microRNAs (miRNAs), which originate from endogenous long selfcomplementary precursors that mature in a multi-step process involving many enzymes [50,51]. Recently, a
Table 4: Simple sequence repeats (SSRs) statistics*

\begin{tabular}{lll}
\hline Dinucleotide repeat & Number of di-pSSR & $\%$ \\
\hline AG & 205 & 83.3 \\
AT & 23 & 9.4 \\
AC & 18 & 7.3 \\
Total & 246 & 100 \\
\hline Trinucleotide repeat & Number of tri-pSSR & $\%$ \\
\hline AAC & & \\
AAG & 41 & 5.7 \\
AAT & 471 & 66.0 \\
ACC & 22 & 3.1 \\
ACG & 18 & 2.5 \\
ACT & 14 & 2.0 \\
AGC & 4 & 0.6 \\
AGG & 25 & 3.5 \\
ATC & 54 & 7.6 \\
CCG & 48 & 6.6 \\
Total & 17 & 2.4 \\
\hline Tetranucleotide repeat & 714 & 100 \\
\hline AAAC & Number of tetra-pSSR & $\%$ \\
AAGG & & \\
AATC & 8 & 8.7 \\
AATG & 7 & 7.6 \\
AATT & 4 & 4.3 \\
ATCG & 3 & 3.3 \\
ACTC & 2 & 2.2 \\
AAGC & 2 & 1.1 \\
ACAT & 1 & 1.1 \\
AAAG & 1 & 1.1 \\
AAAT & 16 & 17.3 \\
Total & & \\
\hline & & \\
\hline & & \\
\hline & & \\
\hline & & \\
\hline & & \\
\hline
\end{tabular}

*The number of di-, tri- and tetranucleotide repeats identified in the melon database is shown for the complete set of putative SSRs (pSSRs).

comprehensive strategy to identify new miRNA homologs in EST databases has been developed $[52,53]$. We have followed this strategy to identify potential melon miRNAs. A total of 20 ESTs that contained homologs to miRNAs in the microRNA Registry database [54] were identified and grouped into 12 contigs and, after manual inspection of secondary foldback hairpin structure, 5 unigenes were selected (Table 8). Contig sequences varied between 536 and 840 nucleotides long, and had negative folding free energies of -206.8 to $-160.8 \mathrm{kcal} \mathrm{mol}^{-1}$ (Table 8 ) according to MFOLD [55], which are in the range of the computational values of Arabidopsis miRNA precursors [52]. Their predicted secondary structures showed that there were at least 16 nucleotides paired between the sequence of the potential mature miRNA and its opposite arm (miRNA*) in the corresponding hairpin structure (Fig. 3). The location of the potential miRNAs varied among ESTs, 4 were found in the sense orientation of the EST, 1 was found in 
Table 5: Localization of simple sequence repeats (SSRs) with respect to putative initiation and termination codons in the melon sequence dataset*

\begin{tabular}{|c|c|c|c|c|c|c|c|c|}
\hline & \multicolumn{2}{|c|}{ Dinucleotide repeats } & \multicolumn{2}{|c|}{ Trinucleotide repeats } & \multicolumn{2}{|c|}{ Tetranucleotide repeats } & \multicolumn{2}{|c|}{ All SSRs analyzed } \\
\hline & No. & $\%$ & No. & $\%$ & No. & $\%$ & No. & $\%$ \\
\hline 5'-UTR & 65 & $82.3 \%$ & $12 \mid$ & $51.7 \%$ & 18 & $62.1 \%$ & 204 & $59.6 \%$ \\
\hline ORF & 0 & $0.0 \%$ & 99 & $42.3 \%$ & 2 & $6.9 \%$ & 101 & $29.5 \%$ \\
\hline 3'-UTR & 13 & $16.5 \%$ & 13 & $5.6 \%$ & 9 & $31.0 \%$ & 35 & $10.2 \%$ \\
\hline Othert & 1 & $1.3 \%$ & 1 & $0.4 \%$ & 0 & $0.0 \%$ & 2 & $0.6 \%$ \\
\hline Total & 79 & $100.0 \%$ & 234 & $100.0 \%$ & 29 & $100.0 \%$ & 342 & $100 \%$ \\
\hline
\end{tabular}

*Only full length melon unigenes were used for this analysis. Full length unigenes were automatically selected by checking the presence of the start codon by comparison of the 5'-terminal region of the unigene with the corresponding Arabidopsis gene used for annotation. IImprecise localization of the SSR with respect to putative initiation or termination codons.

the antisense orientation. We have also searched for potential targets of the potential miRNAs in the melon EST dataset, identifying 3 of them (Table 8). However, minimal folding free energy indexes (MFEIs) [53] were below the -0.85 cut-off value proposed by Zhang et al. [53] only for m 12 (Table 8). Potential melon miRNA m 12 has a precursor of $536 \mathrm{nt}$ in length and codes for a melon ortholog of the Arabidopsis miR319. miR319 targets a transcription factor of the TCP family [56,57]; in the melon dataset, an ortholog of this Arabidopsis gene has been found in a unigene annotated as a TCP transcription factor. In this case, the melon miRNA and its potential target have a pattern of paired/non-paired bases between the target and the miRNA identical to the corresponding target-miRNA pattern in Arabidopsis (data not shown).

\section{Genes potentially encoding pathogen resistance and fruit quality traits}

Pathogens affect severely the productivity of melon crops. Three of the cDNA libraries sequenced here correspond to pathogen-infected tissues and, thus, should contain transcripts from genes whose expression is induced in response infection. We have carried out a bioinformatics search for homologs of genes involved in pathogen resistance response (see [58] for a review) and virus susceptibility [59-61], finding among them at least one melon ortholog to the Arabidopsis FLS2 receptor [62], several unigenes potentially encoding disease resistance proteins as well as mitogen-activated protein kinases, homologs to translation initiation factors constituting potential virus susceptibility factors, etc. [see Additional file 1].

Fruit development and ripening are the most important processes determining the fruit quality traits of fleshy fruits like melon. At present most of the molecular and genetic data available about fruit development and ripening come from tomato $[63,64]$ and Arabidopsis $[65,66]$. In recent years, several genes and quantitative trait loci controlling fruit quality traits have been described in melon $[67,68]$. As for developmental processes, homologs to genes involved in melon fruit development, ripening and quality have been found in the melon dataset. These include several MADS-box genes, homologs to the fw2.2 and ovate QTLs [69,70], several homologs to

Table 6: Single nucleotide polymorphisms (SNPs) statistics*

\begin{tabular}{|c|c|c|c|}
\hline Variation & & Number & $\%$ \\
\hline pSNP transversions: & & 127 & 35.7 \\
\hline pSNP transitions: & & 229 & 64.3 \\
\hline $\mathrm{pSCH}$ transversions: & & 4,273 & 30.4 \\
\hline pSCH transitions: & & 9,801 & 69.6 \\
\hline Mutation & Number of pSNP & Mutation & Number of $\mathrm{pSCH}$ \\
\hline$A<->C$ & 28 & $A<->C$ & 859 \\
\hline$A<->G$ & 117 & $A<->G$ & 5,860 \\
\hline$A<->T$ & 37 & $A<->T$ & 1,897 \\
\hline$C<->G$ & 29 & $C<->G$ & 431 \\
\hline$C<->T$ & 112 & $C<->T$ & $3,94 I$ \\
\hline$G<->T$ & 33 & $G<->T$ & 1,086 \\
\hline
\end{tabular}

*Type and number of transition and transversions are shown for putative single nucleotide variations in sequence (pSCH) and for putative highquality single nucleotide polymorphism (PSNP) identified in the melon database. 
Table 7: Functional annotation statistics

\begin{tabular}{lll}
\hline A. Number of unigenes with BLAST hits & & Number of unigenes \\
\hline Database* & 11,724 & 70.5 \\
\hline Arabidopsis & 5,340 & 32.1 \\
Cucurbitaceae & 11,893 & 71.5 \\
Uniref90 & 13,019 & 78.3 \\
Any database & & $\%$ \\
\hline B. Number of unigenes with HMMER hits & & Number of unigenes \\
\hline Database* & 4,655
\end{tabular}

C. Number of unigenes with orthologue

\begin{tabular}{lll}
\hline Database* & Number of unigenes & $\%$ \\
\hline Arabidopsis & 6,673 & 40.1 \\
\hline
\end{tabular}

* Databases searched were: Arabidopsis [6,109]; Uniref90 [1 10,1 15]; Cucurbitaceae: all cucurbitaceae sequences available in the National Center for Biotechnology Information (NCBI); any database: results using Arabidopsis, cucurbitaceae and Uniref90 databases all together; Pfam [49,II2].

members of the SBP-box gene family to which the major tomato ripening gene COLORLESS NON-RIPENING belongs [71], several ACC synthase and ACC oxidase genes, unigenes from several cell wall-metabolism enzymes, etc [see Additional file 1].

\section{Expression analysis of selected ESTs by Real-Time-qPCR}

The accumulation of transcripts for 20 selected genes was analyzed by reverse transcription Real-Time-qPCR. ESTs for this analysis were preferentially chosen among those showing significant similarity with genes related to response to infection and fruit quality characteristics in melon and other species, and included CTL1, EIF4A-2, EIF4E, EIN4, GA2OX1, HSP101, HSP70, IAA9, LSM1, LUT2, NCBP, SVP, HIR, TCH4, TIP4, TOM1, TOM2A, TOM3, UGE5 and WRKY70 (Table 9). Preliminary experiments were carried out to choose between GAPDH and CYCLOPHILIN (CYP7) RNAs as endogenous controls; results showed that the CYP7 RNA levels varied the least among treatments (data not shown) and, therefore, transcript accumulation levels were expressed relative to CYP7 RNA levels.

Figure 4A illustrates the alteration of the RNA accumulation levels of selected genes that occurred in photosynthetic cotyledons after CMV infection. A significant increase in the level of transcripts from HSP101, HSP70, HIR, TOM2A, WRKY70 and EIN4 was observed; for HSP101, HSP70, WRKY70 and EIN4, transcript accumulation levels in inoculated cotyledons were up to five times greater than in uninoculated controls (Fig. 4A). All of these genes, except TOM2A, have been shown to be responsive to virus infection in other hosts [72-74]. Notably, the expression of EIF4E, known to be required for MNSV multiplication [27], remained unaltered. A shutoff of host gene expression also occurs in association with virus infection [75]; for the set of genes analysed here, only GA2OX1 and NCBP responded to CMV infection with a reduction in the accumulation of their transcripts.

The response of selected genes in roots inoculated with $M$. cannonballus was analysed in melon genotypes known to be susceptible (cultivar "Piel de sapo"; Fig. 4B) and partially resistant (accession pat81 of C. melo L. ssp. agrestis; Fig. 4C) to the infection by this fungus. The patterns of transcript accumulation resulted clearly different for both genotypes. For pat81 (resistant), transcription factors WRKY70 and SVP increased their expression between 2 and 3 times after inoculation; other stress-inducible genes (HSP101, HSP70) showed only a moderate increase (Fig. 4C). For "Piel de sapo" (susceptible), accumulation of WRKY70 and SVP transcripts only increased about 1.5 times after inoculation whereas the expression of HSP101 showed a marked increase (Fig. 4B). It is also worth noting the differential response of the GA2OX1 gene in the two genotypes. Expression of GA2OX1 increased about 1.5 times in pat 81 roots after the $M$. cannonballus attack, whereas it decreased in "Piel de sapo" roots after fungal infection (compare Figs. 4B and 4C).

Comparison of patterns of transcript accumulation at two stages of fruit development showed increased levels of 

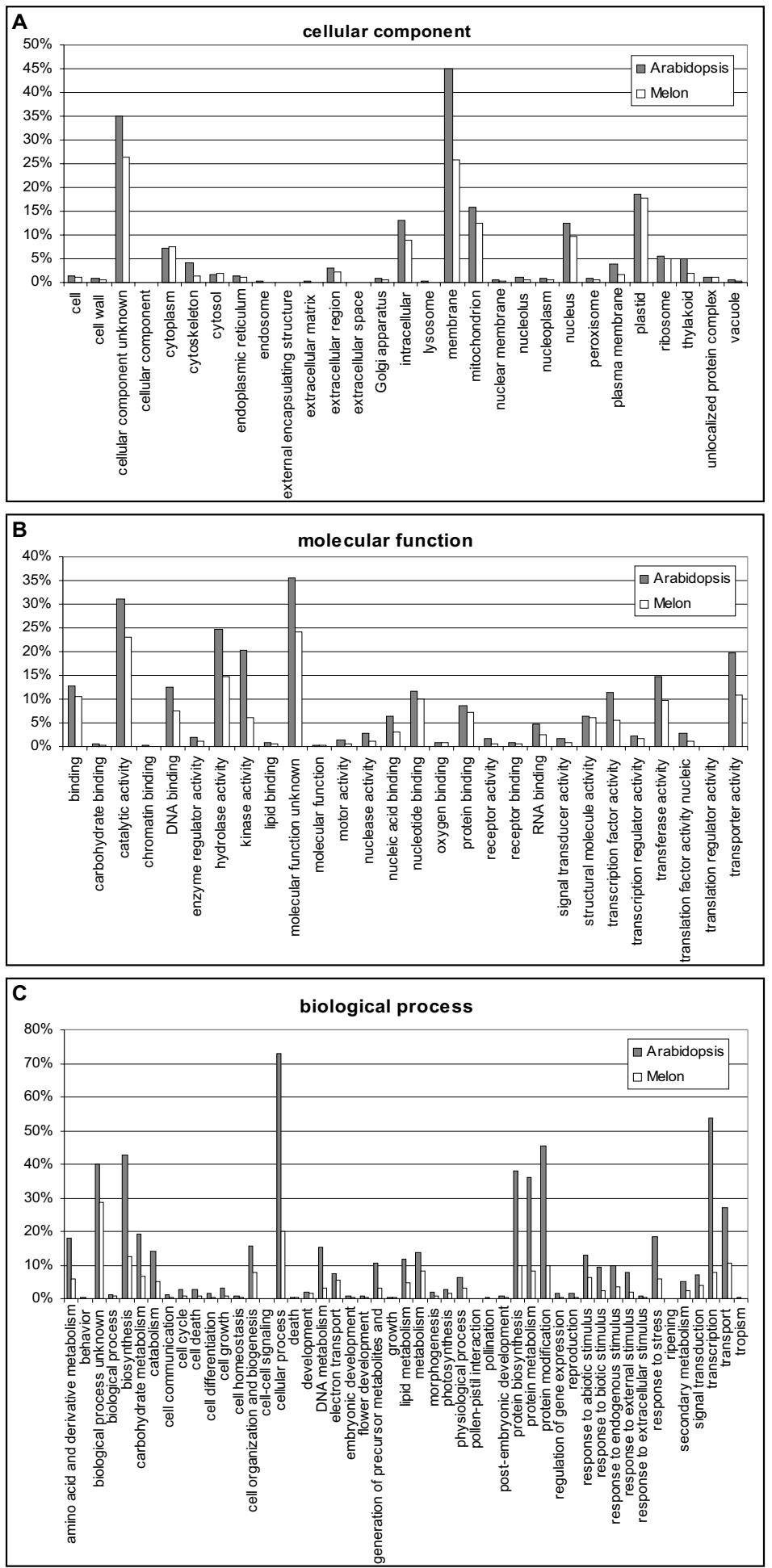

Figure 2

Distribution of melon and Arabidopsis unigenes according to the Gene Ontology scheme for functional classification of gene products. 
Table 8: Potential melon miRNAs

\begin{tabular}{|c|c|c|c|c|c|c|}
\hline Name & $\begin{array}{l}\text { Potential mature miRNA } \\
\text { sequence }\left(5^{\prime}->3^{\prime}\right)^{*}\end{array}$ & Melogen unigenet & $\begin{array}{l}\text { Precursor folding free } \\
\text { energy }(\mathrm{kcal} \mathrm{mol}-1)^{\S}\end{array}$ & $\begin{array}{l}\text { MFEI } \\
\left(\mathrm{kcal} \mathrm{mol}^{-1}\right)^{\Delta}\end{array}$ & $\begin{array}{l}\text { miRNA } \\
\text { family }\end{array}$ & Potential target in melon \\
\hline $\mathrm{m} 2$ & ugaagcugccagcaugaucu & bCL2353Contigl & -206.8 & -0.67 & $\operatorname{miR} 167$ & -- \\
\hline $\mathrm{m} 4$ & ugauugagccgugccaauauc & bPSI_40-FI0-MI3R_c & -195.0 & -0.66 & miRI7I & bHS_39-CI2-MI3R_c \\
\hline $\mathrm{m} 7$ & ucggaccaggcuucauucccc & bA_3I-D02-MI3R_c & -160.8 & -0.70 & $\operatorname{miR} 166$ & -- \\
\hline m8 & uugacagaagauagagagcac & bCl_04-H02-MI3R_c & -188.2 & -0.74 & $\operatorname{miR} 157$ & bCl_30-A09-MI3R_c \\
\hline $\mathrm{m} / 2$ & uuggacugaagggagcucccu & bI5d_24-H05-MI3R_c & -163.6 & -0.86 & $\operatorname{miR} 319$ & bCL2243Contig I \\
\hline
\end{tabular}

*Nucleotide sequences correspond to potential mature miRNA sequences as deduced from BLAST searches using known plant miRNA sequences [54] and analysis of secondary structure predictions [52]. †Accession numbers (MELOGEN database) of potential precursors of melon miRNAs are given. §Computational values of folding free energies have been calculated using MFOLD 3.I [55]. $\triangle$ Minimal folding free energy indexes (MFEls) have been calculated as described by Zhang et al. [53].

gene expression for 9 of the analysed genes. This was particularly evident for HSP70, TOM2A, TOM3, EIN4 and IAA9. In contrast, decreased levels of transcript accumulation were observed for the other 11 genes.

\section{Discussion}

In this paper we provide an initial platform for functional genomics of melon by the identification of more than 16,000 unigenes assembled from almost 30,000 ESTs sequenced from 8 melon cDNA libraries. It is probably premature to estimate the proportion of melon genes represented in this dataset, but based on available data for other plant species (i.e. Arabidopsis and rice), it is likely that the melon unigene set characterised here represents approximately between half and one-third of the number of expressed, protein coding genes of melon. Libraries were constructed from various tissue types, but with a bias towards fruit development and pathogen-infected tissues. Data from these libraries will become a useful resource of
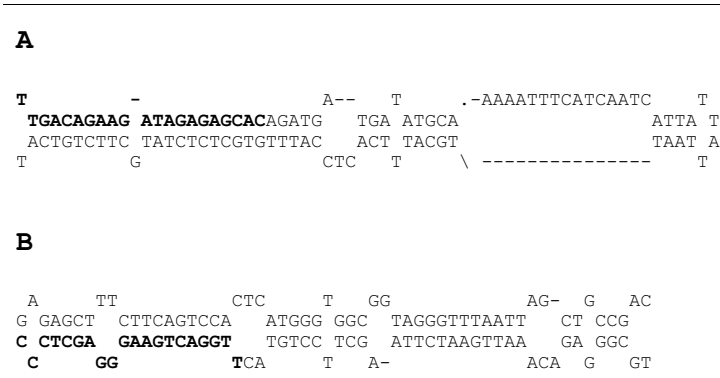

\section{Figure 3}

Potential precursors of melon microRNAs. (A) Stem loop sequence of putative precursor miRNA corresponding to unigene bCl_04-H02-MI3R_c. (B) Stem loop sequence of putative precursor miRNA corresponding to unigene bI5d_24-H05-MI3R_c. The mature miRNA sequences are shown in bold. genes for experiments aimed at understanding important processes involved in fruit development and resistance to viral and fungal pathogens. Also, data presented here provide an important tool for generating markers to saturate melon genetic maps.

In contrast to typical EST gene-sampling strategies reported previously, we have found a low degree of redundancy in the sequences determined. The process of clustering reduced the number of sequences to $56 \%$, from 29,604 good quality ESTs to 6,023 contigs and 10,614 singletons. Contigs with more than 8 ESTs were scarce, the majority of them being formed by 3 or 2 ESTs. Redundancy of the sequences derived from each library ranged from $13 \%$ to $20 \%$, with singletons constituting approximately one third of the unigenes determined per library. This low redundancy is probably due to the success of the normalization process, responsible for the suppression of superabundant transcripts specific for a given tissue or condition. Normalization precludes in silico analysis of gene expression, but greatly increases the number of unigenes that can be determined by reducing redundancy [76]. Here we have used a recently described normalization protocol which is based on the cleavage of DNA or DNA-RNA duplexes by a specific DNase [77]; this process, in our hands, has proven simple, reproducible and efficient. Another factor that has contributed to the low redundancy values obtained has been the sequencing of libraries from very distinct tissues. Thus, the number of library specific unigenes was about one half of the total number of unigenes contributed by each library, suggesting that further sequencing of the libraries still has the potential to provide a good number of new, non-redundant sequences.

cDNA sequences are a useful source of SSRs, which are excellent molecular markers due to their high degree of polymorphism. A common feature of cDNA sequences obtained from plants is the high frequency of SSRs that they contain [36]. We have identified more than 1,000 potential SSRs in the melon dataset, with approximately 
Table 9: Transcripts selected from the database for gene expression analysis by Real Time qPCR

\begin{tabular}{|c|c|c|c|c|c|}
\hline Gene & Melogen unigene & Sequence length (bp) & Arabidopsis locus & $\begin{array}{l}\text { Aminoacid } \\
\text { similarity (\%) }\end{array}$ & Annotation (HMMR domain) \\
\hline CTLI & bCLI 465Contigl & I,387 & ATIG05850 & 66.8 & $\begin{array}{l}\text { Chitinase-like protein I, similar to class I chitinase } \\
\text { (Glyco_hydro_I9) }\end{array}$ \\
\hline CYP 7 & bCL3337ContigI & 801 & AT5G587I0 & 78.4 & Peptidyl-prolyl cis-trans isomerase, cyclophilin \\
\hline EIF4A-2 & bCL2906Contigl & 1,146 & ATIG54270 & 92.6 & Eukaryotic translation initiation factor 4A-2 (DEAD) \\
\hline EIF4E & bCL47|0Contig| & 815 & AT4G I 8040 & 77.5 & Eukaryotic translation initiation factor 4E I (IF4E) \\
\hline EIN4 & bCLI742Contigl & 829 & AT3G04580 & 55.7 & Ethylene receptor (Response_reg) \\
\hline GA2OXI & bCLI3|3Contig| & 1,454 & ATIG78440 & 59.9 & Gibberellin 2-oxidase (2OG-Fell_Oxy) \\
\hline HSPIOI & bCl_38-FII-MI3R_c & 726 & ATIG743I0 & 73.4 & Heat shock protein I0I (AAA_2) \\
\hline HSP70 & bPSI_4I-D06-MI3R_c & 819 & AT5G09590 & 86.8 & Heat shock protein 70/HSC70-5 (HSP70) \\
\hline IAA9 & bCLI34IContigI & 1,672 & AT5G65670 & 51.2 & $\begin{array}{l}\text { Auxin-responsive protein/indoleacetic acid- induced } \\
\text { protein } 9 \text { (AUX_IAA) }\end{array}$ \\
\hline LSMI & bHS_37-FII-MI3R_c & 766 & AT3GI4080 & 72.4 & $\begin{array}{l}\text { Small nuclear ribonucleoprotein/snRNP, putative/Sm } \\
\text { protein, putative, similar to U6 snRNA-associated } \\
\text { Sm-like protein }\end{array}$ \\
\hline LUT2 & bCL3563Contigl & 1,082 & AT5G57030 & 75.5 & Lycopene epsilon cyclase (Lycopene_cycl) \\
\hline NCBP & bCLI83Contigl & $|, 08|$ & AT5G I8II0 & 85.3 & Novel cap-binding protein (IF4E) \\
\hline SVP & bCL2852Contigl & 826 & AT2G22540 & 54.9 & $\begin{array}{l}\text { Short vegetative phase protein, MADS box } \\
\text { transcription factor related cluster (SRF-TF) }\end{array}$ \\
\hline$H I R$ & bCLI44Contigl & 1,266 & ATIG69840 & 89.7 & $\begin{array}{l}\text { Band } 7 \text { family protein, strong similarity to } \\
\text { hypersensitive-induced response protein (Band_7) }\end{array}$ \\
\hline $\mathrm{TCH} 4$ & bCLI2|2Contig| & 1,228 & AT5G57560 & 65.9 & $\begin{array}{l}\text { Xyloglucan:xyloglucosyl transferase/xyloglucan } \\
\text { endotransglycosylase/endo- xyloglucan transferase/ } \\
\text { TCH4 }\end{array}$ \\
\hline TIP4 & bA_23-BI2-MI3R_c & 751 & AT2G258I0 & 50.5 & Tonoplast intrinsic protein (MIP) \\
\hline TOMI & bCL44|6Contigl & 780 & AT4G2I 790 & 75.4 & Transmembrane protein-related/TOMI (DUFI084) \\
\hline TOM2A & bCL3|I5Contigl & 1,113 & ATIG32400 & 60.1 & Senescence-associated family protein \\
\hline TOM3 & bPSI_36-E03-MI3R_c & 857 & ATIGI4530 & & $\begin{array}{l}\text { Tobamovirus multiplication protein } 3 / \mathrm{THHI} \\
\text { (DUFI084) }\end{array}$ \\
\hline UGE5 & bCLII53ContigI & 1,313 & AT4G 10960 & 70.9 & $\begin{array}{l}\text { UDP-glucose 4-epimerase/UDP-galactose 4- } \\
\text { epimerase/Galactowaldenase (Epimerase) }\end{array}$ \\
\hline WRKY70 & bA_25-B0I-MI3R_c & 889 & AT3G56400 & 42.1 & $\begin{array}{l}\text { WRKY family transcription factor, DNA-binding } \\
\text { protein (WRKY) }\end{array}$ \\
\hline
\end{tabular}

$6 \%$ of the melon unigenes containing di-, tri- or tetranucleotide repeats. A clear bias toward AG and AAG repeats existed, that account for $67 \%$ of the SSRs. In contrast, the $\mathrm{GC}$ repeat was not found in the melon dataset. A similar bias toward AG and against CG repeats has been identified in Arabidopsis and other plant species [40,78]. As proposed at least in one other instance [40], this may be due to the tendency of $\mathrm{CpG}$ sequences to be methylated [79], which potentially might inhibit transcription. Another interesting feature of melon SSRs relates to their pattern of localization with respect to putative initiation and termination codons. It is known that the UTRs of transcribed sequences are richer in SSRs than coding regions, particularly at the 5 '-UTRs $[36,40]$. However, in the melon dataset, a high proportion of SSRs $(29.5 \%)$ were found in ORFs. An analysis of the localization of di, tri- and tetranucleotide repeats separately showed that di- and tetranucleotides were preferentially located in UTRs, whereas trinucleotides localised in both, UTRs and ORFs, consistently with maintenance of the ORFs coding capacity. Thus, the prevalence of trinucleotide repeats in the melon dataset $(71 \%)$ explains this result.
We identified in the melon sequence dataset 356 highquality SNPs. Since non-redundant sequences analysed here encompassed $4.5 \mathrm{Mb}$, one SNP was found every $12,000 \mathrm{pb}$ of sequence. This small figure is probably due to the limited number of melon genotypes used and the low redundancy found among libraries. In fact, when the frequency of SNPs is computed in relation to the length and number of contigs containing SNPs, the corresponding value (one SNP in every 616 bp of sequence) is of the same order of magnitude as values previously calculated for melon (441 bp; [80]) and other plant species [40]. With the advent of high-throughput detection systems, the SSRs and SNPs identified here will constitute an important resource for mapping and marker-assisted breeding in melon and closely related crops.

As an approach to the function of melon unigenes, we carried out a bioinformatics analysis based on BLASTX and matches with the Pfam database [49]. The proportion of melon unigenes with no similar sequences in databases was quite high, suggesting that the melon dataset may encompass an important number of melon-specific 

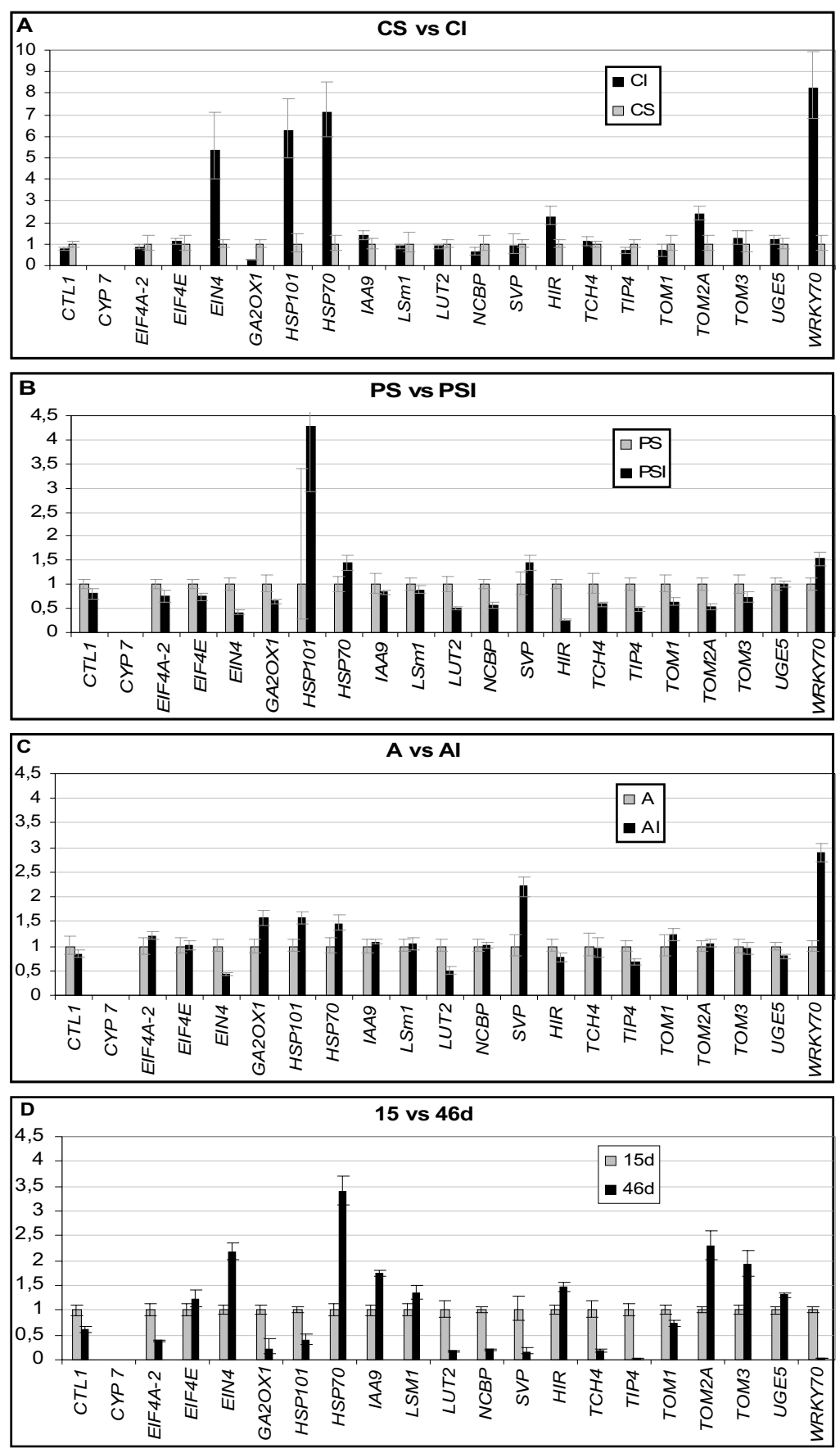

Figure 4

Transcripts analyzed by Real Time qPCR. (A) Pattern of transcripts accumulation in CMV-infected melon cotyledons (Cl) relative to that of healthy cotyledons (CS). (B) Pattern of transcripts accumulation in $M$. cannonballus infected roots of $C$. melo L. cv. "Piel de sapo" (PSI) relative to that of healthy roots (PS). (C) Pattern of transcripts accumulation in $M$. cannonballus infected roots of $C$. melo $\mathrm{L}$. ssp. agrestis (AI) relative to that of healthy roots $(A)$. (D) Pattern of transcripts accumulation in fruits of 15 days after pollination of C. melo L. cv. "Piel de sapo" (I5d) relative to that of fruits of 46 days after pollination (46d). cy: cyclophilin endogenous control; see Table 9 for the rest of genes. 
sequences. However, the proportion specific sequences might be overestimated because blasting has been made with unigene sequences, which in many cases do not cover the complete length of the transcript. We performed a functional classification of the unigenes following the Gene Ontology scheme, which is one of the more versatile and complete systems for functional classification [48]. A comparison of the distributions of melon and Arabidopsis unigenes in GO categories showed that both followed similar tendencies, suggesting that the melon dataset is representative of the whole melon transcriptome. This is remarkable, as the number of different libraries sequenced has been relatively small; again, this is probably due to the success of the normalization process. We have also carried out specific searches for genes involved in pathways of particular relevance in melon, such are resistance response and fruit development, identifying a remarkable number of melon candidates. For example, an ortholog of the flagellin receptor FLS2 from Arabidopsis [62] has been identified, together with 163 candidate RLKs that may have critical roles in pathogen recognition or diverse signalling processes. Similarly, up to 8 MADSbox gene homologs with potential roles in development have been found in the melon dataset. Moreover, a bioinformatics approach [52,53] allowed the identification of potential precursors of melon miRNAs together with several potential targets in the melon dataset. This finding opens the door to biotechnology approaches based on the use of artificial miRNAs to specifically silence melon genes [81,82].

The transcript accumulation analysis for the 20 selected genes revealed important changes in gene expression associated with pathogen infection and fruit development. For virus infection, the accumulation of transcripts remained unaltered for 12 genes, but showed a significant increase for 6 genes and a decrease for 2. Among the set of genes analysed, TOM2A and EIF4E were known to code for virus susceptibility factors $[27,83]$; the expression of TOM2A was increased after CMV infection, consistently with its requirement by the virus, but this was not the case for EIF4E. Different hypotheses can explain this result: since EIF4E is an abundant, housekeeping protein, increased expression may not be essential for virus multiplication; alternatively, CMV may not use EIF4E in melon or may use a factor coded by a different member of the 4E family; it may also be that timing of the sampling for this experiment was not appropriate to detect such an effect, as requirement of EIF4E might occur very early during virus multiplication. In the cases of infection of susceptible ("Piel de sapo") and resistant (pat81) melons by M. cannonballus, more extensive alterations in gene expression seemed to occur in the susceptible than in the resistant accession. Significantly, for the susceptible accession, stress responsive genes (e.g. HSP101) appeared to be max- imally induced, whereas for the resistant accession, a gene encoding a WRKY70 transcription factor, potentially involved in resistance response, was induced to high levels. Significantly, expression of GA2OX1 increased about 1.5 times in pat81 after the $M$. cannonballus attack, whereas it decreased in "Piel de sapo". GA2ox is a major gibberellin (GA) catabolic enzyme, with an important role in controlling GA levels in plants. Hormones control many plant developmental processes, and strong evidence indicates that hormone signalling is involved in the regulation of root growth and architecture [84,85]. The differential response of the GA2OX1 gene in the two melon genotypes is consistent with an enhanced root growth in pat81 after infection [86]. Notably, other genes involved in hormone-mediated signalling pathways, such as the IAA9 gene, did not show such differential response to $M$. cannonballus infection in both genotypes. In the case of fruit development, differences in the expression of selected genes between immature and ripening fruits appeared to be even sharper than in the cases of healthy and pathogen-infected tissues. Specific roles during fruit development for HSP70, TOM2A and TOM3 have not been identified, though an increased expression has been shown at least in the case of TOM2A in tomato [87]. The ethylene receptor gene EIN4 showed a two-fold increase in expression. EIN4 is the ortholog of Arabidopsis EIN4 and tomato LeETR4 [88,89]. In tomato, LeETR4 is also highly expressed in ripening fruit, suggesting that it responds by modulating ethylene signalling during ripening [63]. The MADS-box gene (SVP) showed about a fourfold decrease in expression. This gene is the ortholog of tomato JOINTLESS, which specifies the abscission zone in tomato. In tomato fruit microarray hybridizations, the expression of JOINTLESS also decreased from 7 to 57 DAP [87], in agreement with our data for melon. The lycopene epsilon cyclase (LUT2) and xyloglucan endotransglycosylase (TCH4) genes showed an approximately four-fold decrease in expression during melon fruit development. These findings fit with the patterns of expression of these genes in tomato, where their transcript levels decrease to a non-detectable level in the ripe fruits $[90,91]$.

\section{Conclusion}

In summary, this collection of ESTs represents a substantial increase on the information available for melon. The dataset contains SSR and SNP markers that can be used for breeding, as well as a significant number of candidate genes that can be experimentally tested for their roles in various important processes. This set of genes constitutes also the basis for a microarray for melon that is being used in experiments to further analyse fruit development and maturation and responses to pathogen infections. 


\section{Methods \\ Plant material}

The cDNA libraries were prepared using material from four different melon genotypes: the line T-111 (Semillas Fitó, Barcelona, Spain), which corresponds to a Piel de Sapo breeding line, the Piel de Sapo cultivar "Piñonet torpedo" (Semillas Batlle, Barcelona, Spain), the accession C35 of the germplasm collection of La Mayora-CSIC (EELM-CSIC, Málaga, Spain), which corresponds to a cantaloupe-type of melon, and the accession pat 81 of C. melo L. ssp. agrestis (Naud.) Pangalo maintained at the germplasm bank of COMAV (COMAV-UPV, Valencia, Spain) (Table 1). Seeds of line T-111 were germinated at $30^{\circ} \mathrm{C}$ for two days and plants were grown in a greenhouse in peat bags, drip irrigated, with 0.25 -m spacing between plants. Fruits of 15 and 46 days after pollination were collected and mesocarp tissues were recovered and used for RNA extractions. Root samples were from Piel de sapo and pat81 plants, both healthy and inoculated with M. cannonballus. Piel de sapo is fully susceptible to the infection by this fungus whereas pat81 has been shown to be partially resistant $[92,93]$. Seeds were pre-germinated in Petri dishes. After 4 days, seedlings were transplanted to 0.5-1 pots filled with sterile soil substrate and grown in a greenhouse $\left(20-35^{\circ} \mathrm{C}, 60-85 \%\right.$ relative humidity). Inoculations were carried out by adding 50 colony-forming units (CFU) of $M$. cannonballus per gram of sterile soil as described by Iglesias et al. [94]. Fourteen days after inoculation, healthy and inoculated roots were collected for RNA extraction. The presence of the fungus and the infection levels were assessed by real-time quantitative PCR as described by Picó et al. [95]. CMV infected cotyledons were collected from plants of the C-35 accession. In this case, seeds were pregerminated in Petri dishes for $24 \mathrm{~h}$ at $28^{\circ} \mathrm{C}$ in the dark, planted in $0.5-\mathrm{l}$ pots and maintained in an insect-proof green house $\left(20-28^{\circ} \mathrm{C}, 45\right.$ to $85 \%$ relative humidity) for 6 to 7 days, until the first true leaf started emerging. At this stage, cotyledons were mechanically inoculated with CMV following standard procedures [96]. Inoculated cotyledons were harvested 4 days after inoculation and used for RNA extractions. Dot-blot hybridisation [97] was used to check infection by CMV. Plants of the C-35 accession were also used for collecting healthy leaves. Plants were maintained in the greenhouse for 21 days, and second and third leaves above cotyledons were harvested for RNA extractions.

\section{Construction of cDNA libraries and EST sequencing}

Total RNA was prepared as described by Aranda et al. [98]. Poly $\left(\mathrm{A}^{+}\right)$RNA from total RNA was purified using MicroPoly $\left(\mathrm{A}^{+}\right)$Purist (Ambion, Austin, TX, USA), a celluloseoligo(dT)-based method. Integrity and quality of both total and poly $\left(\mathrm{A}^{+}\right) \mathrm{RNA}$ were tested by gel electrophoresis. cDNA libraries were constructed with the SMART cDNA Library Construction kit (Clontech, Mountain View, CA,
USA), using a modified primer to include a $S f i$ I enzyme restriction site. A normalization step was carried out with TRIMMER kit (Evrogen, Moscow, Russia). After normalization, a cDNA fractionation step was performed with SizeSep 400 Spun Columns (Amersham Biosciences, Buckinghamshire, England). cDNA was digested with $S f i$ I, generating $S f i$ IA-Sfi IB cohesive ends for directional cloning into a modified version of BlueScript SK plasmid vector (Stratagene, La Jolla, CA, USA). Ligation products were transformed into $E$. coli electrocompetent cells DH10B (Invitrogen, Carlsbad, CA, USA) by electroporation. The titer of the libraries was evaluated by plating an aliquot on LB agar plates with ampicillin at $100 \mu \mathrm{g} \mathrm{ml}^{-1}$. Only libraries of $10^{5} \mathrm{cfu} \mathrm{ml}^{-1}$ or more were considered as acceptable. Prior to large scale sequencing, the average insert size was estimated by restriction analyses of 24 plasmid DNA minipreps per library from randomly picked colonies.

Sequencing was carried out from the 5 '-end of the inserts without library amplification using the universal M13 reverse primer. An external custom service was contracted for this task (Macrogen Inc., Seoul, Korea). Approximately 6,000 clones were sequenced from the CI library, and 3,500 clones were sequenced from each of the other libraries (Table 2). Sequences obtained in this work can be found in GenBank [accession numbers AM713476 to $\underline{\text { AM743079] }}$ and MELOGEN [44].

\section{Bioinformatics}

EST sequences were automatically trimmed, clustered and annotated using the EST2uni analysis pipeline [43]. EST2uni compromises the analysis pipeline written in PERL [99], a database (MySQL) [100] and a web site to browse the results coded in PHP [101]. Thus, for the EST pre-processing step, base calling was performed with Phred [102], low quality regions and vector sequences were trimmed with Lucy [103], and repeats and low complexity regions were masked with RepeatMasker [104] and Seqclean [105]. Further vector contamination was also eliminated with Seqclean using NCBI's UniVec [106]. High-quality EST sequences were then assembled to obtain the unigene set using Tgicl [105].

Detection of SSRs was performed using Sputnik [107]. Putative SNPs were annotated when the least represented allele was present in two EST sequences or more. ORFs were predicted in the ESTs with the aid of the ESTScan software [108].

For functional annotation, comparisons against the Arabidopsis (TAIR) [109] and Uniref [110] databases were carried out using BLASTN or BLASTX for nucleotide or protein sequences, respectively. Functional domains were searched with HMMPFAM [111] using the Pfam database 
[112]. The Gene Ontology (GO) classification [48] was derived from the BLASTN results against the Arabidopsis proteome. Also, a bi-directional BLASTN comparison was performed in order to obtain a set of putative orthologs with Arabidopsis. Finally, a set of superunigenes was obtained grouping different unigenes with the same expected mRNA target, as judged by extensive sequence overlapping.

To assess codon usage, we generated a set of melon sequences predicted to contain full-length coding regions. These sequences were subjected to BLASTX and, after manual inspection, sequences showing a high similarity to Arabidopsis proteins were selected to ensure that no sequences containing frame-shift errors were included in the analysis. From this smaller dataset, which included 588 sequences, ORFs were defined and a codon usage table was created. Codon usage was calculated from sequences using the GCUA program [113]. All codons were found in the dataset, with the least frequent codon represented 134 times.

To identify potential melon miRNAs, the 33,292 melon ESTs were subjected to a BLAST search against mature sequences of known miRNAs from the miRNA Registry Database (released January 2007) [54] using BLASTN [47]. ESTs with only 0-1 mismatched nucleotides with known miRNAs were considered. Selected ESTs were subjected to a BLAST search against protein databases in order to remove potential protein-coding sequences. ESTs pertaining to the same melon unigene of the MELOGEN database were grouped. The secondary structures of the unigenes encoding potential miRNA precursors were predicted with the web-based tool MFOLD [55], using default parameters. In each case, only the lower energy structure was selected for visual inspection, as previously described $[52,114]$. In order to select unigenes with perfect or near-perfect secondary foldback hairpin structures, only sequences with a maximum size of 3 nucleotides for a bulge in the miRNA sequence and with at least 16 paired nucleotides between the mature sequence and the opposite arm were considered as potential miRNA candidates. In addition, the minimal folding free energy index (MFEI) for each sequence was calculated following Zhang et al. [53].

\section{Gene expression analyses}

Real time quantitative PCR was performed with an $A B$ 7500 System (Applied Biosystems, Foster City, CA, U.S.A) to quantify mRNA corresponding to some transcripts of interest, in the tissues and physiological conditions used for library construction. Twenty ESTs representing these transcripts were chosen from the database and used to generate gene-specific primers (Table 10) with Primer Express Software (Applied Biosystems). The chemistry used for PCR product detection was the Power SYBR green dye (Applied Biosystems) and ROX as passive reference. CYCLOPHILIN served as endogenous control (sequence extracted from the database), $\Delta \Delta \mathrm{Ct}$ was the method of calculation to perform relative quantification, and three technical replicates were carried out and considered for statistical analysis. Melting curves analyses at the end of

Table 10: Primer sequences for Real Time-qPCR analysis of transcript accumulation

\begin{tabular}{lll}
\hline Gene & Primer sequence $\left(5^{\prime}->3^{\prime}\right)$ Forward & Reverse \\
\hline CTLI & tgggccatgttggctctaag & ctcccgtgacaactccatca \\
CYP 7 & cgatgtggaaattgacggaa & cggtgcataatgctcggaa \\
EIF4A-2 & ttccegaggtttcaaagatca & ccaatgcttctggtggcact \\
EIF4E & ttcggttccttccttccat & ccgccgatgtagctttcatc \\
EIN4 & tgcaacgtgactgctgtttct & tctggcatgtgaagatccaaga \\
GA2OXI & tagggcaaatcggttagcga & ccaaatgcaaaccgattgaa \\
HSPI0I & aacgtatggtgcggattgaca & tccaccttcatggtatccaacat \\
HSP70 & gctgaggcgtaccttggaaa & atcctgccagcatcctttgt \\
IAA9 & gacggaaagccaggttcaag & cccctccatactcacttcacaa \\
LSMI & ctacttcgagatgggcggaa & tcaccaacgatcaccctttca \\
LUT2 & gctggcgtggaacactcttt & cgaatgccttcaatgtccagt \\
NCBP & cgtcggtctgcttaatttgca & cgcctacgaactccattgaca \\
SVP & cgaggcaggtcacgttctct & agagaagacgaggagcgcaa \\
HIR & tgacgggctcagagacagtg & gttccagggacgttttcagc \\
TCH4 & ggagggtagccttgagggaat & ctggacattgctcgacaacaa \\
TIP4 & tccttgctggtgtcggatc & cgtttgccaataacgcattg \\
TOMI & gggagaaggaagaaacttcatgag & gcgtcaaaagcggataaagc \\
TOM2A & ctcctcagcagccgaagaaa & tggacccgctaaaacaccac \\
TOM3 & aatggagttcgggctgttgt & aaggcaaggcttggcatgt \\
UGE5 & gcgaaagtgtccaaaagcca & acacaagctttttgcatccgt \\
WRKY70 & ggattgctcctggcctgac & tcggctgcttttcttcgatc \\
\end{tabular}


the process and No Template Controls (NTC) were carried out to ensure product-specific amplification and no primer-dimer quantification. A control reaction as for reverse transcription but without the enzyme was performed to evaluate genomic DNA contamination.

\section{Authors' contributions}

Daniel Gonzalez-Ibeas prepared RNAs for two libraries, constructed the eight libraries, carried out the gene expression analysis by Real-Time-qPCR and participated in the bioinformatics analyses and in the drafting of the manuscript. José Blanca carried out the bioinformatics analyses, EST database and web page, and participated in the drafting of the manuscript. Cristina Roig and Belén Picó prepared RNAs for the root libraries and participated in the drafting of the manuscript. Mireia González-To, Wim Deleu and Jordi Garcia-Mas prepared RNAs from melon fruits and participated in the drafting of the manuscript. Pere Puigdomènech is the main coordinator of The MELOGEN Project and participated in the conception of the study together with Pere Arús, Fernando Nuez, Jordi Garcia-Mas and Miguel A. Aranda. Miguel A. Aranda is the principal investigator or this work, supervised it and wrote the manuscript. All authors read and approved the final manuscript.

\section{Additional material}

\section{Additional file 1}

Genes potentially encoding pathogen resistance and fruit quality traits. Genes were identified in the melon data set by comparison with the Arabidopsis database $[6,109]$. A brief description, the corresponding Arabidopsis locus and the HMMR domain identified are given for each unigene.

Click here for file

[http://www.biomedcentral.com/content/supplementary/14712164-8-306-S1.pdf]

\section{Acknowledgements}

This work was supported by grants from Ministerio de Educación y Ciencia (Spain) (GEN2003-20237-C06) and Consejería de Educación y Cultura (Región de Murcia, Spain) (BIO2005/04-6436). Wim Deleu, Cristina Roig and Daniel Gonzalez-lbeas are recipient of a postdoctoral fellowship from the Centre de Recerca en Agrigenòmica CSIC-IRTA (Spain), a Juan de la Cierva grant from Ministerio de Educación y Ciencia (Spain) and a predoctoral fellowship from Ministerio de Educación y Ciencia (Spain), respectively.

\section{References}

I. FAOSTAT Agriculture data [http://faostat.fao.org/default.aspx]

2. Jayasooriya AP, Sakono M, Yukizaki C, Kawano M, Yamamoto K Fukuda N: Effects of Momordica charantia powder on serum glucose levels and various lipid parameters in rats fed with cholesterol-free and cholesterol-enriched diets. J Ethnopharmacol 2000, 72:33I-336.

3. Arumuganathan K, Earle ED: Nuclear DNA content of some important plant species. Plant Mol Biol Rep 1991, 9:208-218.
4. Goff SA, Ricke D, Lan TH, Presting G, Wang R, Dunn M, Glazebrook J, Sessions A, Oeller P, Varma H, others: A Draft Sequence of the Rice Genome (Oryza sativa L. ssp. japonica). Science 2002, 296:92-100.

5. Yu J, Hu S, Wang J, Wong GK-S, Li S, Liu B, Deng Y, Dai L, Zhou Y, Zhang $X$, others: A Draft Sequence of the Rice Genome (Oryza sativa L. ssp. indica). Science 2002, 296:79-92.

6. Arabidopsis Genome Initiative: The Arabidopsis Information Resource (TAIR): a comprehensive database and web-based information retrieval, analysis, and visualization system for a model plant. Nucleic Acids Res 200 I, 29: 102-105.

7. Kirkbride JH: Biosystematic monograph of the genus Cucumis (Cucurbitaceae) Boone, North Carolina: Parkway Publishers; 1993.

8. Garcia-Mas J, Monforte AJ, Arus P: Phylogenetic relationships among Cucumis species based on the ribosomal internal transcribed spacer sequence and microsatellite markers. Plant Syst Evol 2004, 248:19I-203.

9. Liu L, Kakihara F, Kato M: Characterization of six varieties of Cucumis melo L. based on morphological and physiological characters, including shelf-life of fruit. Euphytica 2004, 135:305-313.

10. Miccolis V, Saltveit ME: Morphological and physiological changes during fruit growth and maturation of seven melon cultivars. J Am Soc Hort Sci 1991, I | 6: 1025-1029.

II. Shalit M, Katzir N, Tadmor Y, Larkov O, Burger Y, Shalekhet F, Lastochkin E, Ravid U, Amar O, Edelstein M, others: Acetyl-CoA: Alcohol acetyltransferase activity and aroma formation in ripening melon fruits. J Agric Food Chem 200I, 49:794-799.

12. Bauchot AD, Mottram DS, Dodson AT, John P: Effect of Aminocyclopropane-I-carboxylic Acid Oxidase Antisense Gene on the Formation of Volatile Esters in Cantaloupe Charentais Melon (Cv. Védrandais). J Agric Food Chem 1998, 46:4787-4792.

13. Flores F, El Yahyaoui F, de Billerbeck G, Romojaro F, Latche A, Bouzayen M, Pech JC, Ambid C: Role of ethylene in the biosynthetic pathway of aliphatic ester aroma volatiles in Charentais Cantaloupe melons. J Exp Bot 2002, 53:20I-206.

14. Yahyaoui FEL, Wongs-Aree C, Latche A, Hackett R, Grierson D, Pech JC: Molecular and biochemical characteristics of a gene encoding an alcohol acyl-transferase involved in the generation of aroma volatile esters during melon ripening. FEBS J 2002, 269:2359-2366.

15. Hadfield KA, Bennett AB: Polygalacturonases: Many Genes in Search of a Function. Plant Physiol 1998, I I 7:337-343.

16. Rose JKC, Hadfield KA, Labavitch JM, Bennett AB: Temporal sequence of cell wall disassembly in rapidly ripening melon fruit. Plant Physiol 1998, I I 7:345-361.

17. Bennett $A B$ : Biochemical and genetic determinants of cell wall disassembly in ripening fruit: A general model. Hortscience 2002, 37:447-450.

18. Haritatos E, Keller F, Turgeon R: Raffinose oligosaccharide concentrations measured in individual cell and tissue types in Cucumis melo $L$ leaves: Implications for phloem loading. Planta 1996, 198:614-622.

19. Volk GM, Turgeon R, Beebe DU: Secondary plasmodesmata formation in the minor-vein phloem of Cucumis melo $L$ and Cucurbita pepo L. Planta 1996, 199:425-432.

20. Gomez G, Torres H, Pallas V: Identification of translocatable RNA-binding phloem proteins from melon, potential components of the long-distance RNA transport system. Plant J 2005, 4I:107-II6.

21. Chen JQ, Rahbé Y, Delobel B, Sauvion N, Guillaud J, Febvay G: resistance to the aphid Aphis gossypii: behavioural analysis and chemical correlations with nitrogenous compounds. Entomol Exp Appl 1997, V85:33-44.

22. Luo MZ, Wang YH, Frisch D, Joobeur T, Wing RA, Dean RA: Melon bacterial artificial chromosome (BAC) library construction using improved methods and identification of clones linked to the locus conferring resistance to melon Fusarium wilt (Fom-2). Genome 2001, 44:154-162.

23. Klingler J, Powell G, Thompson GA, Isaacs R: Phloem specific aphid resistance in Cucumis melo line AR 5: effects on feeding behaviour and performance of Aphis gossypii. Entomol Exp Appl 1998, 86:79-88.

24. Marco CF, Aguilar JM, Abad J, Gomez-Guillamon ML, Aranda MA: Melon resistance to Cucurbit yellow stunting disorder virus 
is characterized by reduced virus accumulation. Phytopathology 2003, 93:844-852.

25. Diaz JA, Nieto C, Moriones E, Truniger V, Aranda MA: Molecular characterization of a Melon necrotic spot virus strain that overcomes the resistance in melon and nonhost plants. Mol Plant-Microbe Interact 2004, 17:668-675.

26. Klingler J, Creasy R, Gao LL, Nair RM, Calix AS, Jacob HS, Edwards $O R$, Singh KB: Aphid resistance in Medicago truncatula involves antixenosis and phloem-specific, inducible antibiosis, and maps to a single locus flanked by NBS-LRR resistance gene analogs. Plant Physiol 2005, 137: | 445-1455.

27. Nieto C, Morales M, Orjeda G, Clepet C, Monfort A, Sturbois B, Puigdomenech P, Pitrat M, Caboche M, Dogimont C, others: An elF4E allele confers resistance to an uncapped and non-polyadenylated RNA virus in melon. Plant / 2006, 48:452-462.

28. Perin C, Hagen L, Conto VD, Katzir N, Danin-Poleg Y, Portnoy V, Baudracco-Arnas S, Chadoeuf J, Dogimont C, Pitrat M: A reference map of Cucumis melo based on two recombinant inbred line populations. Theor Appl Genet 2002, 104:1017-1034.

29. Gonzalo MJ, Oliver M, Garcia-Mas J, Monfort A, Dolcet-Sanjuan R, Katzir N, Arus P, Monforte A: Simple-sequence repeat markers used in merging linkage maps of melon (Cucumis melo L.). Theor Appl Genet 2005, I l 0:802-8I I.

30. Eduardo I, Arus P, Monforte AJ: Development of a genomic library of near isogenic lines (NILs) in melon (Cucumis melo L.) from the exotic accession PII 6 I375. Theor Appl Genet 2005, I I 2:139-| 48.

31. Ayub R, Guis M, BenAmor M, Gillot L, Roustan JP, Latche A, Bouzayen $M$, Pech JC: Expression of ACC oxidase antisense gene inhibits ripening of cantaloupe melon fruits. Nat Biotechnol 1996, 14:862-866

32. Guis M, Roustan JP, Dogimont C, Pitrat M, Pech JC: Melon biotechnology. Biotechnol Genet Engng Rev 1998, I 5:289-3I I.

33. Gaba V, Zelcer A, Gal-On A: Cucurbit biotechnology - The importance of virus resistance. In Vitro Cell Dev Biol Plant 2004, 40:346-358.

34. Rudd S: Expressed sequence tags: alternative or complement to whole genome sequences? Trends Plant Sci 2003, 8:32I-329.

35. Alba R, Fei Z, Payton P, Liu Y, Moore SL, Debbie P, Cohn J, D'Ascenzo $M$, Gordon JS, Rose JKC, others: ESTs, cDNA microarrays, and gene expression profiling: tools for dissecting plant physiology and development. Plant / 2004, 39:697-7|4.

36. Morgante $M$, Hanafey M, Powell W: Microsatellites are preferentially associated with nonrepetitive DNA in plant genomes. Nat Genet 2002, 30:194-200.

37. Rafalski JA: Novel genetic mapping tools in plants: SNPs and LD-based approaches. Plant Sci 2002, 162:329-333.

38. Ouyang S, Zhu W, Hamilton J, Lin H, Campbell M, Childs K, ThibaudNissen F, Malek RL, Lee Y, Zheng L, others: The TIGR Rice Genome Annotation Resource: improvements and new features. Nucleic Acids Res 2007, 35:D883-D887.

39. Fei Z], Tang XM, Alba R, Giovannoni J: Tomato Expression Database (TED): a suite of data presentation and analysis tools. Nucleic Acids Res 2006, 34:D766-D770.

40. Newcomb RD, Crowhurst RN, Gleave AP, Rikkerink EHA, Allan AC, Beuning LL, Bowen JH, Gera E, Jamieson KR, Janssen BJ, others: Analyses of expressed sequence tags from apple. Plant Physiol 2006, 141:147-166.

4I. Goes da Silva F, landolino A, Al Kayal F, Bohlmann MC, Cushman MA Lim H, Ergul A, Figueroa R, Kabuloglu EK, Osborne C, others: Characterizing the Grape Transcriptome. Analysis of Expressed Sequence Tags from Multiple Vitis Species and Development of a Compendium of Gene Expression during Berry Development. Plant Physiol 2005, I39:574-597.

42. Forment J, Gadea J, Huerta L, Abizanda L, Agusti J, Alamar S, Alos E, Andres F, Arribas R, Beltran JP, others: Development of a citrus genome-wide EST collection and cDNA microarray as resources for genomic studies. Plant Mol Biol 2005, 57:375-39I.

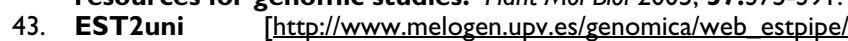
index.php]

44. MELOGEN database [http://www.melogen.upv.es]

45. Sterky F, Bhalerao RR, Unneberg P, Segerman B, Nilsson P, Brunner AM, Charbonnel-Campaa L, Lindvall IJ, Tandre K, Strauss SH, others: A Populus EST resource for plant functional genomics. Proc Natl Acad Sci USA 2004, 10 I: 13951-13956.
46. Hsiang $\mathrm{T}$, Goodwin $\mathrm{PH}$ : Distinguishing plant and fungal sequences in ESTs from infected plant tissues. J Microbiol Methods 2003, 54:339-35I.

47. Altschul SF, Madden TL, Schaffer AA, Zhang J, Zhang Z, Miller W, Lipman DJ: Gapped BLAST and PSI-BLAST: a new generation of protein database search programs. Nucleic Acids Res 1997, 25:3389-3402.

48. The Gene Ontology Consortium: Gene Ontology: tool for the unification of biology. Nat Genet 2000, 25:25-29.

49. Finn RD, Mistry J, Schuster-Bockler B, Griffiths-Jones S, Hollich V Lassmann T, Moxon S, Marshall M, Khanna A, Durbin R, others: Pfam: clans, web tools and services. Nucleic Acids Res 2006, 34:D247-D25I.

50. Carrington JC, Ambros V: Role of microRNAs in plant and animal development. Science 2003, 301:336-338.

51. Bartel DP: MicroRNAs: Genomics, biogenesis, mechanism, and function. Cell 2004, I I 6:28I-297.

52. Zhang BH, Pan XP, Cannon CH, Cobb GP, Anderson TA: Conservation and divergence of plant microRNA genes. Plant J 2006, 46:243-259.

53. Zhang BH, Pan XP, Cox SB, Cobb GP, Anderson TA: Evidence that miRNAs are different from other RNAs. Cell Mol Life Sci 2006, 63:246-254

54. Griffiths-Jones S: The microRNA Registry. Nucleic Acids Res 2004, 32:DI09-DIII.

55. Zuker M: Mfold web server for nucleic acid folding and hybridization prediction. Nucleic Acids Res 2003, 31:3406-34I5.

56. Palatnik JF, Allen E, Wu XL, Schommer C, Schwab R, Carrington JC Weigel D: Control of leaf morphogenesis by microRNAs. Nature 2003, 425:257-263

57. Gustafson AM, Allen E, Givan S, Smith D, Carrington JC, Kasschau KD: ASRP: the Arabidopsis Small RNA Project Database. Nucleic Acids Res 2005, 33:D637-D640.

58. Chisholm ST, Coaker G, Day B, Staskawicz B]: Host-microbe interactions: Shaping the evolution of the plant immune response. Cell 2006, I 24:803-8I4.

59. Kushner DB, Lindenbach BD, Grdzelishvili VZ, Noueiry AO, Paul SM, Ahlquist P: Systematic, genome-wide identification of host genes affecting replication of a positive-strand RNA virus. Proc Natl Acad Sci USA 2003, 100:15764-15769.

60. Diaz-Pendon JA, Truniger V, Nieto C, Garcia-Mas J, Bendahmane A, Aranda MA: Advances in understanding recessive resistance to plant viruses. Mol Plant Pathol 2004, 5:223-233.

61. Robaglia C, Caranta C: Translation initiation factors: a weak link in plant RNA virus infection. Trends Plant Sci 2006, I I:40-45.

62. Gomez-Gomez L, Boller T: FLS2: An LRR receptor-like kinase involved in the perception of the bacterial elicitor flagellin in Arabidopsis. Mol Cell 2000, 5:1003-I0II.

63. Giovannoni J]: Genetic regulation of fruit development and ripening. Plant Cell 2004, 16:SI70-SI80.

64. Tanksley SD: The genetic, developmental, and molecular bases of fruit size and shape variation in tomato. Plant Cell 2004, 16:SI8I-SI89.

65. Pinyopich A, Ditta GS, Savidge B, Liljegren SJ, Baumann E, Wisman E, Yanofsky MF: Assessing the redundancy of MADS-box genes during carpel and ovule development. Nature 2003, 424:85-88.

66. Dinneny JR, Weigel D, Yanofsky MF: A genetic framework for fruit patterning in Arabidopsis thaliana. Development 2005, I32:4687-4696.

67. Pitrat M: $\mathbf{2 0 0 2}$ gene list for melon. Cucurbit Genet Coop Rep 2002, 25:76-93.

68. Monforte AJ, Oliver M, Gonzalo MJ, Alvarez JM, Dolcet-Sanjuan R, Arus $P$ : Identification of quantitative trait loci involved in fruit quality traits in melon (Cucumis melo L.). Theor Appl Genet 2004, 108:750-758.

69. Frary A, Nesbitt TC, Frary A, Grandillo S, van der Knaap E, Cong B, Liu JP, Meller J, Elber R, Alpert KB, others: fw2.2: A quantitative trait locus key to the evolution of tomato fruit size. Science 2000, 289:85-88.

70. Liu JP, Van Eck J, Cong B, Tanksley SD: A new class of regulatory genes underlying the cause of pear-shaped tomato fruit. Proc Natl Acad Sci USA 2002, 99:13302-13306.

7I. Manning K, Tor M, Poole M, Hong Y, Thompson AJ, King G], Giovannoni J], Seymour GB: A naturally occurring epigenetic mutation in a gene encoding an SBP-box transcription factor inhibits tomato fruit ripening. Nat Genet 2006, 38:948-952. 
72. Aranda MA, Escaler M, Wang D, Maule AJ: Induction of HSP70 and polyubiquitin expression associated with plant virus replication. Proc Natl Acad Sci USA 1996, 93:I 5289-I 5293.

73. Escaler M, Aranda MA, Roberts IM, Thomas CL, Maule AJ: A comparison between virus replication and abiotic stress (heat) as modifiers of host gene expression in pea. Mol Plant Pathol 2000 , I:I59-167.

74. Whitham SA, Yang CL, Goodin MM: Global impact: Elucidating plant responses to viral infection. Mol Plant-Microbe Interact 2006, 19:1207-1215

75. Aranda $M$, Maule $A$ : Virus-induced host gene shutoff in animals and plants. Virology 1998, 243:26I-267.

76. Bonaldo MDF, Lennon G, Soares MB: Normalization and subtraction: Two approaches to facilitate gene discovery. Genome Res 1996, 6:79|-806

77. Zhulidov PA, Bogdanova EA, Shcheglov AS, Vagner LL, Khaspekov GL, Kozhemyako VB, Matz MV, Meleshkevitch E, Moroz LL, Lukyanov SA, others: Simple cDNA normalization using kamchatka crab duplex-specific nuclease. Nucleic Acids Res 2004, 32:e37.

78. Zhang LD, Yuan DJ, Yu SW, Li ZG, Cao YF, Miao ZQ, Qian HM, Tang $\mathrm{KX}$ : Preference of simple sequence repeats in coding and non-coding regions of Arabidopsis thaliana. Bioinformatics 2004, 20: $1081-1086$

79. Finnegan EJ, Genger RK, Peacock WJ, Dennis ES: DNA methylation in plants. Annu Rev Plant Physiol Plant Mol Biol 1998, 49:223-247.

80. Morales M, Roig E, Monforte AJ, Arus P, Garcia-Mas J: Singlenucleotide polymorphisms detected in expressed sequence tags of melon (Cucumis melo L.). Genome 2004, 47:352-360.

81. Niu QW, Lin SS, Reyes JL, Chen KC, Wu HW, Yeh SD, Chua NH: Expression of artificial microRNAs in transgenic Arabidopsis thaliana confers virus resistance. Nat Biotechnol 2006 24: $\mid 420-1428$

82. Schwab R, Ossowski S, Riester M, Warthmann N, Weigel D: Highly specific gene silencing by artificial microRNAs in Arabidopsis. Plant Cell 2006, I 8: II21-II33.

83. Yamanaka T, Imai T, Satoh R, Kawashima A, Takahashi M, Tomita K, Kubota K, Meshi T, Naito S, Ishikawa M: Complete inhibition of tobamovirus multiplication by simultaneous mutations in two homologous host genes. J Virol 2002, 76:249I-2497.

84. Malamy JE: Intrinsic and environmental response pathways that regulate root system architecture. Plant Cell Environ 2005, 28:67-77.

85. Radi A, Dina P, Guy A: Expression of sarcotoxin IA gene via a root-specific tob promoter enhanced host resistance against parasitic weeds in tomato plants. Plant Cell Rep 2006 25:297-303.

86. Dias RDS, Pico B, Espinos A, Nuez F: Resistance to melon vine decline derived from Cucumis melo ssp agrestis: genetic analysis of root structure and root response. Plant Breeding 2004, I 23:66-72.

87. Tomato expression database [http://ted.bti.cornell.edu]

88. Sakai H, Hua J, Chen QHG, Chang CR, Medrano LJ, Bleecker AB, Meyerowitz EM: ETR2 is an ETRI-like gene involved in ethylene signaling in Arabidopsis. Proc Natl Acad Sci USA 1998 95:5812-5817.

89. Tieman DM, Klee HJ: Differential expression of two nove members of the tomato ethylene-receptor family. Plant Physiol 1999, I 20:165-172.

90. Ronen G, Cohen M, Zamir D, Hirschberg J: Regulation of carotenoid biosynthesis during tomato fruit development: Expression of the gene for lycopene epsilon-cyclase is downregulated during ripening and is elevated in the mutant Delta. Plant J 1999, I 7:341-351.

91. Catala C, Rose JKC, Bennett AB: Auxin-regulated genes encoding cell wall-modifying proteins are expressed during early tomato fruit growth. Plant Physiol 2000, I 22:527-534

92. Esteva I, Nuez F: Field resistance to melon dieback in Cucumis melo L. Cucurbit Genet Coop 1994, I 7:76-77.

93. Iglesias A, Pico B, Nuez F: A temporal genetic analysis of disease resistance genes: resistance to melon vine decline derived from Cucumis melo var. agrestis. Plant Breeding 2000 I 1 9:329-334.

94. Iglesias A, Picó B, Nuez F: Artificial inoculation methods and selection criteria for breeding melons against vine decline. Acta Hortic 2000, 5 1 0:155-162.
95. Picó B, Roig C, Fita A, Nuez F: Detección de Monosporascus cannonballus en raíces de melón mediante PCR cuantitativa en tiempo real. Acta Port Hortic 2005, 7:169-176.

96. Hull S: Matthews's plant Virology San Diego: Academic Press; 2002

97. Sambrook J, Rusell DW: Molecular cloning A laboratory manual. New York: CSHL PRESS; 200I

98. Aranda MA, Escaler M, Thomas CL, Maule AJ: A heat shock transcription factor in pea is differentially controlled by heat and virus replication. Plant J |999, 20:|53-|6|.

99. PERL [http://www.perl.org]

100. MySQL [http://www.mysql.com]

10I. PHP [http://www.php.net]

102. Ewing B, Hillier L, WendI MC, Green P: Base-calling of automated sequencer traces using Phred. I. Accuracy assessment. Genome Res 1998, 8:175-185.

103. Chou $\mathrm{HH}$, Holmes $\mathrm{MH}$ : DNA sequence quality trimming and vector removal. Bioinformatics 200I, I7:1093-I 104.

104. RepeatMasker [http://www.repeatmasker.org]

105. DFCl Gene Indices Software Tools [http://compbio.dfci.har vard.edu/tgi/software/]

I06. NCBI's UniVec [http://www.ncbi.nlm.nih.gov/VecScreen/Uni Vec.html]

107. Sputnik [http://capb.dbi.udel.edu/main/ssr-proj/ssr-file/descrip tion.html]

108. ESTScan software [http://www.isrec.isb-sib.ch/ftp-server/ESTS can/]

109. TAIR: the Arabidopsis information resource [http://www.ara bidopsis.org/]

I I0. Uniref [http://www.ebi.ac.uk/uniref/]

III. Eddy SR: Profile hidden Markov models. Bioinformatics I998, I 4:755-763.

I 12. Pfam database [http://www.sanger.ac.uk/Software/Pfam/]

I 13. Mclnerney JO: GCUA (General Codon Usage Analysis). Bioinformatics 1998, 14:372-373.

I 14. Reinhart BJ, Weinstein EG, Rhoades MW, Bartel B, Bartel DP: MicroRNAs in plants. Genes Dev 2002, 16:1616-1626.

I 15. Apweiler R, Bairoch A, Wu CH, Barker WC, Boeckmann B, Ferro S, Gasteiger E, Huang H, Lopez R, Magrane M, others: UniProt: the Universal Protein knowledgebase. Nucleic Acids Res 2004 32:D||5-DII9.

Publish with BioMed Central and every scientist can read your work free of charge

"BioMed Central will be the most significant development for disseminating the results of biomedical research in our lifetime. "

Sir Paul Nurse, Cancer Research UK

Your research papers will be:

- available free of charge to the entire biomedical community

- peer reviewed and published immediately upon acceptance

- cited in PubMed and archived on PubMed Central

- yours - you keep the copyright
BioMedcentral 